\title{
The role of mindfulness and spiritual intelligence in students' mental health
}

Ebrahim Nemati ${ }^{1}$, Mojtaba Habibi ${ }^{2}$, Fahime Ahmadeian Vargahan ${ }^{3}$, Sepide Soltan Mohamadloo ${ }^{3}$,Said Ghanbari ${ }^{4}$

\author{
Journal of Research \& Health \\ Social Development \& Health Promotion \\ Research Center \\ Vol. 7, No. 1, Jan \& Feb 2017 \\ Pages: 594- 602. \\ DOI: 10.18869/acadpub.jrh.7.1.594 \\ Original Article
}

1. Department of Family Counseling, Faculty of Family Counseling, Shahid Beheshti University, Tehran, Iran

2. Correspondence to: Department of Health Psychology, Family Institute, Shahid Beheshti University, Tehran, Iran

Email: babakhabibius@yahoo.com

3. Department of Clinical Psychology, Faculty of Clinical Psychology, University of Medical Sciences, Tehran, Iran

4. Department of Counseling, Faculty of Education and Psychology, Shahid Beheshti University, Tehran, Iran

Received: 12 Jan 2014

Accepted: 15 Sep 2014

How to cite this article: Nemati E, Habibi M, Ahmadeian Vargahan F, Soltan Mohamadloo S, Ghanbari S. The role of mindfulness and spiritual intelligence in students' mental health. $J$ Research \& Health2017; 7(1): 594- 602.

\begin{abstract}
Studies show that mental disorders are highly prevalent among students. Therefore, the present study aimed to examine the role of mindfulness and spiritual intelligence in the students' mental health studying at university of medical sciences. The study population included all undergraduate and medicine students. A total of 393 female and male students (193 medical and 200 non-medical students) were selected through randomly. General Health Questionnaire (GHQ) and spiritual intelligence and mindfulness questionnaire were used to evaluate the participants. The results revealed the negative correlation of mental health with mindfulness and spiritual intelligence and a positive correlation between mindfulness and dimensions of spiritual intelligence. Also, the dimension of spiritual life (43.1\%) and mindfulness (31\%) had a significant negative effect on the explained variance of the students' mental health. Analysis of variance showed that the scales of mindfulness, perception of existence, somatic symptoms, and anxiety were higher among women. Therefore, the students can be more capable of coping with existing traumas and pressures by boosting their spirituality, consciousness, and mindfulness.
\end{abstract}

Keywords: Mental Health, Mindfulness, Spiritual Intelligence, Students

\section{Introduction}

Health, either individually or socially, is undoubtedly one of the most important aspects of human life. Today, the costs of treating mental disorders have been of interest to the public health officials, so that different societies try to use their cultural wealth along with other therapeutic factors to treat different diseases, including mental disorders [1]. Students are at risk of these problems, as Eisenberg et al. reported the mental health problems are the most important issues among students in higher education [2]. Studies show that mental disorders are highly prevalent among students [3]. A review study by Nemati and et al on mental health research on students revealed that an increase in the prevalence of mental disorders among students [4]. Since education period is a decisive stage in people's lives, the prevalence of mental disorders is 
considered a serious threat to students [5]. Therefore, students' mental health needs to be addressed and followed up in universities more than before.

Mental health is defined as a state representing a high and acceptable level of adaptability and emotional and behavioral adjustment. In other words, a person is considered mentally healthy if they are relatively stable and moderate, with satisfactory level of emotional and behavioral adjustment and enjoying life and being with others [6]. Recently, psychologists have introduced a construct called spiritual intelligence which is effective in mental health and improving the quality of life [7]. Spiritual intelligence as one of the new concepts of intelligence involves a kind of adjustment and problem-solving behavior with the highest levels of growth in different cognitive, moral, emotional, and interpersonal domains and helps the person to adjust with the surrounding phenomena and achieve internal and external integration [8]. According to previous studies, there is a positive correlation between spirituality and well-being [9]. A study revealed a significant positive correlation between the power of spiritual faith and psychological well-being [10]. Spiritual intelligence involves a set of capabilities, capacities, and spiritual resources, the use of which increases the adjustment and improves mental health [11], such that the World Health Organization mentions the physical, psychological, social, and spiritual dimensions when defining the dimensions of human existence, and raises a fourth dimension, i.e. the spiritual dimension in human growth and development [12]. Spiritual intelligence promotes and protects students' mental health [7] and creates happiness [13]. Spiritual intelligence has a negative relationship with depression, aggression, hostility, anxiety, and self-deception and a positive relationship with mood, social sensitivity, satisfaction with life, energy, and activity [14,15].

Spiritual intelligence reminds various methods of consciousness and is applied to integrate the inner essence of thought and soul with the external world [16]. According to Sisk, spiritual intelligence can be defined as a deep consciousness through which a person becomes more and more conscious of the dimensions of self [17]. These definitions of spiritual intelligence have a very close relationship with mindfulness. In fact, mindfulness has been defined as a non-judgmental and reasonable sense of consciousness that helps see and accept emotions and physical phenomena, as they happen [18].

Furthermore, there is a close and significant relationship between the concepts of spiritual intelligence and mindfulness, and several studies have confirmed their relationship with mental health. Mindfulness is associated with low levels of psychotic symptoms, negative emotions, and high levels of positive emotions, self-esteem, and emotional adjustment [18-20]. Mindfulness improves the quality of psychological, physical, emotional, and spiritual well-being [21] and reduces somatic symptoms [22]. The results of the study conducted by Bergomi et al. showed that mindfulness moderates the relationship between inevitable anxiogenic events and symptoms of psychosis [20]. Therefore, mindfulness can contribute to enhancing the ability to deal with inevitable anxiety-causing experiences and reduce the detrimental impact of these experiences on mental health. Results of the study by Tan and Martin revealed a negative correlation between mindfulness and stress, anxiety, depression, and cognitive hardiness, and a positive correlation between mindfulness and self-esteem and progress [23]. Therefore, since fewer studies have been conducted on the role of spiritual intelligence and mindfulness in the mental health of medical students, this study can be of great help to the medical community health.

The role of spiritual intelligence and mindfulness has been proved in creating and boosting people's mental health. Students are exposed to more stressful situations [24], and spiritual experiences are considered potentially healthy [6]. The results of studies suggest that depression, anxiety, and burnout 
have increased [25] and humanitarian attitudes, positive emotion, and physical health have decreased among medical students [26]. Despite health interventions, studies still report high levels of mental disorders and suicidal tendencies among medical students [27] and this trend continues among practicing doctors [26]. Accordingly, this study aimed to examine the predictive role of spiritual intelligence and mindfulness in mental health of students at Shahid Beheshti University of Medical Sciences, as well as the role of demographic factors in mental health, mindfulness, and spiritual intelligence.

\section{Method}

This study was conducted on all undergraduate and medicine students of Tehran Shahid Beheshti University of Medical Sciences in academic year 2012-2013. For sampling, the number of variables, i.e. subscales, gender, being indigenous and non-indigenous, and medical and non-medical was multiplied by 20 . prticipants were selected through randomly and three questionnaires were used to collect data. Totally, 400 questionnaires were distributed to collect data, 393 of which were returned.

General Health Questionnaire (GHQ): This questionnaire was developed by Goldberg and Hillier. It consists of four seven-item subscales (28 items in all), including somatic symptoms, anxiety symptoms, social functioning, and depressive symptoms. Likert scale was used for scoring and the maximum score was 84 . Several studies have been conducted on the validity of the GHQ. In a study conducted by Goldberg and Williams, its validity was reported as $95 \%$. In a study conducted by Keyes, the Cronbach's alpha coefficient of 0.93 was obtained for this questionnaire [28]. According to Noorbala, Bagheri Yazdi, and Mohammad [29], the reliability coefficient of the whole GHQ was 0.96 and that of subscales of depression, anxiety, somatic symptoms, and social dysfunction was $0.94,0.90,0.89$, and 0.87 , respectively.

Spiritual Intelligence Questionnaire: This questionnaire was normalized by Abdullahzadeh,
Keshmiri, and Arab Ameri on the Iranian students in 2008 [30]. It consists of 29 items measuring two factors. The first factor comprises 12 items about "perception of and communication with the origin of existence" and the second factor includes 17 items on the "spiritual life or reliance on inner core". In the study conducted by Abdullahzadeh et al., the reliability of 0.89 was obtained for the questionnaire in the final stage and its face and content validity were confirmed by the opinions of experts and factor analysis, and the correlations of all questions were above 0.3 . In a study conducted by Nemati, Sadeghi, and Ahmadi [30], the reliability of the questionnaire (Cronbach's alpha) was calculated 0.92 through collecting data from 269 participants of Shahid Beheshti University and the total score showed a good and high internal consistency. The Cronbach's alpha coefficients for the internal consistency of the first and second factors of the questionnaire were equal, i.e. 0.87 and 0.87 , respectively. In the present study, the Cronbach's alpha coefficients for the internal consistency of the first and second factors were 0.92 and 0.85 , respectively.

Mindful Attention Awareness Scale (MAAS): This 15 -item scale was developed by Brown and Ryan [18] to assess the level of awareness and attention to the life events and experiences. MAAS measures mindfulness on a 6-point Likert scale (from score 1 for "almost always" to score 6 for "almost never") and gives a total score for mindfulness ranging from 15 to 90 . Higher scores indicate greater mindfulness. The Cronbach's alpha coefficient for the internal consistency of the questions was 0.80 . Sufficient validity was reported for MAAS according to its negative correlation with depression and anxiety assessment tools and its positive correlation with positive affect and self-esteem assessment tools. Test-retest reliability coefficient of the questionnaire was reported to be consistent within a month [18]. To analyze the data, descriptive statistics (mean and standard deviation) and inferential statistics (correlation, multiple regression, 
MANOVA, and two-way ANOVA) were used in SPSS-19.

\section{Results}

A total of 393 people participated in the study, 193 were medical students $(35.4 \%), 250$ were non-medical students (paramedicine, nursing, and psychology) (63.6\%), 4 did not mention their field of study (1\%), 152 were male (38.2\%), 241 female (61.8\%), 337 single $(85.8 \%), 47$ were married (12\%), and 9 did not mention their marital status (2.3\%), 167 were indigenous $(42.5 \%), 214$ were nonindigenous $(54.5 \%)$, and 12 did not mention their place of residence $(3.1 \%)$. The mean age of the prticipants was 22.56 years (range: 22 to 40 years old). Tables 1 and 2 show the descriptive data, including frequency, standard deviation, and mean of the variables of perception of existence, spiritual life, mindfulness, and dimensions of mental health.

Table 1 Mean and standard deviation of the perception of existence, spiritual life, and mindfulness in terms of gender, place of residence, and field of study

\begin{tabular}{cccccccccc}
\hline & & & \multicolumn{2}{c}{$\begin{array}{c}\text { Perception of } \\
\text { existence }\end{array}$} & \multicolumn{2}{c}{ Spiritual life } & \multicolumn{2}{c}{ Mindfulness } \\
\hline & $\begin{array}{c}\text { Place of } \\
\text { residence }\end{array}$ & Field of study & M & SD & M & SD & M & SD & Number \\
& Indigenous & Medical & 48.37 & 8.43 & 64.40 & 7.83 & 7.98 & 15.21 & 27 \\
& & Non-medical & 45.15 & 7.65 & 62.65 & & & 15.26 & 32 \\
Male & Non- & Medical & 45.96 & 10.34 & 64.90 & 9.82 & 56.09 & 12.26 & 32 \\
& Indigenous & Non-medical & 46.54 & 10.51 & 65.43 & 9.37 & 64.37 & 11.76 & 53 \\
\hline \multirow{3}{*}{ Female } & & Medical & 48.11 & 8.20 & 62.76 & 7.09 & 65.11 & 12.6 & 34 \\
& Indigenous & Non-medical & 51.21 & 6.23 & 56.08 & 8.61 & 64 & 12.8 & 74 \\
& Non- & Medical & 48.08 & 8.14 & 64.86 & 9.38 & 65.71 & 11.28 & 45 \\
& Indigenous & Non-medical & 49.04 & 8.05 & 64.07 & 8.65 & 64.5 & 11.25 & 82 \\
\hline
\end{tabular}

Table 2 Mean and standard deviation of dimensions of mental health in terms of gender, place of residence, and field of study

\begin{tabular}{|c|c|c|c|c|c|c|c|c|c|c|c|}
\hline & \multirow[b]{2}{*}{$\begin{array}{l}\text { Place of } \\
\text { residence }\end{array}$} & \multirow[b]{2}{*}{$\begin{array}{l}\text { Field of } \\
\text { Study }\end{array}$} & \multicolumn{2}{|c|}{$\begin{array}{c}\text { Somatic } \\
\text { symptoms }\end{array}$} & \multicolumn{2}{|c|}{ Anxiety } & \multicolumn{2}{|c|}{$\begin{array}{c}\text { Social } \\
\text { functioning }\end{array}$} & \multicolumn{2}{|c|}{ Depression } & \multirow{2}{*}{ Number } \\
\hline & & & $\mathrm{M}$ & SD & M & SD & M & $\mathrm{SD}$ & $\mathrm{M}$ & $\mathrm{SD}$ & \\
\hline \multirow{4}{*}{ Male } & \multirow{2}{*}{ Indigenous } & Medical & 3.07 & 2.09 & 4.18 & 2.94 & 7.07 & 3.25 & 2.59 & 2.48 & 27 \\
\hline & & Non-Medical & 4.5 & 2.99 & 5.84 & 3.79 & 8.4 & 3.39 & 5.78 & 5.39 & 32 \\
\hline & \multirow{2}{*}{$\begin{array}{c}\text { Non- } \\
\text { Indigenous }\end{array}$} & Medical & 4 & 3.58 & 5.9 & 4.77 & 7.21 & 3.13 & 4.25 & 5.55 & 32 \\
\hline & & Non-Medical & 4.58 & 3.22 & 5.13 & 3 & 7.43 & 3.31 & 3.64 & 3.93 & 53 \\
\hline \multirow{4}{*}{ Female } & \multirow{2}{*}{ Indigenous } & Medical & 6.17 & 4.17 & 6.67 & 3.85 & 8.08 & 4.34 & 4.14 & 5.56 & 34 \\
\hline & & Non-medical & 5 & 3.37 & 6.74 & 4.38 & 7.78 & 3.9 & 4.04 & 4.35 & 74 \\
\hline & Non- & Medical & 6.26 & 4.78 & 6.44 & 4.55 & 7.93 & 4.23 & 4.06 & 4.73 & 45 \\
\hline & Indigenous & Non-medical & 5.03 & 3.37 & 5.62 & 4.04 & 7.48 & 3.95 & 3.82 & 4.41 & 82 \\
\hline
\end{tabular}

Correlation coefficient was used to determine the relationship between the variables (mental health, dimensions of spiritual intelligence, and mindfulness) among students (Table 3). In this study, the low score of the participants in GHQ represents their greater health.

As can be seen from Table 3, there is a significant negative correlation between mental health and mindfulness, spiritual life, and perception of existence and a significant positive correlation between mindfulness and spiritual life and perception of existence, as well as a positive correlation between spiritual life and perception of existence. 
Table 3 Correlation coefficients between mental health, mindfulness, and dimensions of spiritual intelligence in students

\begin{tabular}{|c|c|c|c|c|}
\hline Variables & Mental health & Mindfulness & Spiritual life & $\begin{array}{l}\text { Perception of } \\
\text { existence }\end{array}$ \\
\hline \multicolumn{5}{|l|}{ Mental health } \\
\hline Mindfulness & $-0.37 * *$ & & & \\
\hline Spiritual life & $-0.43 * *$ & $0.15 * *$ & & \\
\hline $\begin{array}{l}\text { Perception of the } \\
\text { existence }\end{array}$ & $-0.32 * *$ & $0.13 * *$ & $0.57 * *$ & \\
\hline
\end{tabular}

Therefore, considering the relationship between the variables, the stepwise multiple linear regression was used to determine the predictive proportion of the variables of perception of the existence and spiritual life, and mindfulness on the students' mental health. After entering the predictive variables into the analysis, spiritual life and mindfulness remained in the analysis and perception of existence was removed from the analysis (Table 4).

Table 4 Results of the stepwise multiple regression of the variables of spiritual life and mindfulness on the students' mental health

\begin{tabular}{lccccccccccc}
\hline $\begin{array}{l}\text { Regression } \\
\text { model }\end{array}$ & $\mathrm{R}$ & $\mathrm{R}^{2}$ & $\Delta \mathrm{R}^{2}$ & $\mathrm{~F}$ & $\mathrm{Df}$ & $\mathrm{Sig}$. & $\mathrm{B}$ & $\beta$ & $\mathrm{t}$ & $\mathrm{Sig}$. \\
\hline Step 1* & 0.431 & 0.184 & 0.186 & 89.2 & -3911 & 0.001 & -0.648 & -0.431 & -9.44 & 0.001 \\
Step2* & 0.528 & 0.275 & 0.093 & 75.2 & -3902 & 0.001 & -0.317 & -0.308 & -7.07 & 0.001 \\
\hline
\end{tabular}

* Step 1: Spiritual life

** Step 2: Spiritual life and mindfulness

According to the results shown in Table 4, the variables of spiritual life and mindfulness are significant as predictive variables. In fact, they explain students' mental health and have a significant negative contribution in explaining the variance in the students' mental health. By adding mindfulness in the second step, $9.3 \%$ was added to the explained variance in the second step $\left(\Delta \mathrm{R}^{2}=0.093\right)$. The MANOVA was used to examine the effect of gender (male and female), place of residence (indigenous and non-indigenous), and field of study (medical and non-medical) on the subscales of spiritual intelligence (perception of existence and spiritual life) and dimensions of mental health. Wilks' Lambda test revealed that only the effect of gender on the subscales of the perception of existence and spiritual life $\left(p<0.002, \quad F(2,371)=6.33, \quad \mathrm{n}^{2}=0.033\right), \quad$ and somatic symptoms, anxiety, social functioning, depression $\left(\mathrm{p}<0.001, \mathrm{~F}(4,368)=5.89, \mathrm{p}^{2}=0.060\right)$ showed a significant difference, while the effect of other variables on the subscales of somatic symptoms, anxiety, social functioning, and depression, and subscales of perception of existence and spiritual life indicated no significant difference.

The results of the MANOVA on perception of existence, spiritual life, and dimensions of mental health in terms of gender revealed a significant difference between males and females in the subscales: perception of existence and spiritual intelligence $(\mathrm{p}<0.005$, $F(2,372)=7.94$. Women with a mean score of 49.41 had a greater perception of existence compared to men (46.45), but no significant difference was observed between women and men in the subscale of spiritual life. Regarding the dimensions of mental health, a statistically significant difference was found between male and female students in the scales of somatic symptoms $(\mathrm{p}<0.001, \mathrm{~F}(1,371)=16.23)$ and anxiety $(p<0.01, F(1,371)=6.12)$, but no significant difference was observed in two scales of social functioning and depression.

Two-way ANOVA was used to examine the effect of gender, place of residence, and field of study on the scale of mindfulness. 
The results revealed a significant difference between male and female students in the mean of mindfulness $(p<0.001, F(1,372)=12.29$. The mean of mindfulness in females (65.08) was more than that in males (60.23). However, there was no significant difference between indigenous and non-indigenous, as well as medical and non-medical students in the mean of mindfulness.

\section{Discussion}

The present study aimed to examine the role of mindfulness and dimensions of spiritual intelligence in the students' mental health. The results revealed a negative correlation between mental health and mindfulness and dimensions of spiritual intelligence, and a positive correlation between mindfulness and dimensions of spiritual intelligence. In other words, increased mindfulness led to increased dimensions of spiritual intelligence in students and vice versa. Also, as mindfulness and dimensions of spiritual intelligence increase in students, their mental health enhances and their psychological traumas decrease. According to the stepwise regression, of all the variables studied, spiritual life and mindfulness were the most important factors affecting students' mental health. This finding shows that these two variables can explain the variance in mental health and predict the mental health. In the first step of regression, the dimension of spiritual life explained about $18.4 \%$ of students' mental health. In fact, as spiritual intelligence increases in students, their psychological traumas decrease and their mental health improves. This finding is consistent with the results of some studies that suggest students' spiritual intelligence promotes mental health [7] and causes happiness [13] e.g. Kashdan and Nezlek [9], Pargament and Mahoney [10], King and de Sicko [15] and confirms previous research. According to the definition of spiritual intelligence as a kind of adjustment and problem-solving behavior, it can be stated that students who have higher levels of spiritual intelligence, are more capable of coping with, adjusting to, and solving the problems they may encounter during their education and this capability helps them improve their mental health. Given that spiritual intelligence can shape and organize our perception of events, such as health or illness, it is effective in not only health, but also difficult experiences of life, such as sadness and loss, and also useful for well-being [16]. In fact, this factor can be especially helpful for non-indigenous students who are away from their families and face loneliness. Therefore, it can be stated that spiritual intelligence is involved in a person's thoughts and beliefs, and can play a major role in enhancing and preserving mental health. The second step of regression revealed that mindfulness explained approximately $27.5 \%$ of students' mental health. Hence, as mindfulness increases in students, their mental health improves, and makes them able to accept the realities of student life without distortion and strengthen their ability to accept emotions and promote their mental health. This finding is consistent with those of Kaviani et al. [31], Bergomi et al. [20], Brown and Ryan [18], and Kieviet-Stijnen et al. [22]. Considering the fact that mindful people perceive the internal and external realities without distortion and are strongly capable of dealing with a wide range of thoughts, emotions, and experiences, whether pleasant or unpleasant [32], mindfulness can be useful for the students who are in their late adolescence or early adulthood with its specific characteristics and experience living alone and away from their families for the first time and face different cultural and ethnic groups that may be even opposed to their family culture. Since mindfulness has been known to reduce stress [33], it can help students to organize their thoughts and emotions and make them more coherent, create innovative ideas when facing problems, and select rational and appropriate solutions under academic, financial, and emotional pressures. In general, by strengthening and expanding the power of mindfulness in students, they will be able to adapt themselves to the current situation and feel satisfied with their personal 
and social life.

The effect of gender (male and female), place of residence (indigenous and non-indigenous), and field of study (medical and non-medical) was examined on the dimensions of spiritual intelligence, mental health, and mindfulness, and gender was the only significant variable. Place of residence and field of study were different, but the difference was not statistically significant. Therefore, another result of the study was that females and males were significantly different in the subscale of spiritual intelligence and females had greater perception of existence compared to males. This result is consistent with the findings of Nasr-Esfahani and Etemadi [34], Nemati, Sadeghi, and Ahmadi [30], and Saadati and Lashani [24]. In addition, female students had higher levels of mindfulness, which is consistent with the results of the study by Nemati et al. [30] indicating the mean of mindfulness in women (61.36) is higher than in men (57.61). The difference between women and men in spiritual intelligence and mindfulness can be attributed to their biological and cultural differences. Higher spiritual intelligence and mindfulness in women can be explained considering their emotional character and their multitasking ability, as well as the roles defined for both sexes in the society. Women's higher levels of spiritual intelligence and mindfulness can be attributed to the fact that they have a higher internal locus of control and that people with internal locus of control have higher spiritual intelligence and mindfulness. Furthermore, given that both spiritual intelligence and mindfulness are influenced by parenting style [30] and Iranian parents usually raise their girls and boys differently, the higher level of spiritual intelligence and mindfulness in girls can be influenced by the parenting style. Examining the effect of gender on the dimensions of mental health indicated that there was a statistically significant difference between females and males in the scales of somatic symptoms and anxiety, while no significant difference was observed in the scales of social functioning and depression. On the scales of somatic symptoms and anxiety, female students were more vulnerable and suffered from lower mental health that is consistent with the findings of Sharifi and Sotudehnia [35], Hosseini et al. [36], and Tavakoli, Chinisaz, and Alipour [37]. Since emotions and characters may have a profound effect on the physical function and health [20], females will suffer from more health problems, because they are psychologically more emotional than males in our society. In addition, since girls are more dependent on their families and relatives and do not feel comfortable on the campus and are more vulnerable to stress, they will go through more stressful conditions that will affect their mental health.

\section{Conclusion}

According to the results of the study regarding the effect of the spiritual intelligence and mindfulness on the mental health and the greater vulnerability of the female students, it can be concluded that raising spiritual intelligence, and generally, spirituality, mindfulness, and perception in medical and non-medical students and training how to be mindful will be effective in improving the students' mental health conditions and increasing their ability to deal with damages and existing pressures.

This study had some limitations, including: using the convenience sampling and selecting students only from Iran University of Medical Sciences, due to which it could not be generalized to other students from other universities.

It is recommended that further research be conducted on students from other universities and educational institutions and the cultural and ethnic status of the students be taken into consideration. It is also suggested that workshops be held to increase the level of spirituality and mindfulness in students and experimental studies be conducted on the students' mindfulness.

\section{Acknowledgements}

We thank for all students the Shahid Beheshti university of medical sciences, Tehran, who 
have the necessary cooperation in completing the questionnaire.

\section{Contribution}

The idea and design of the study and writing: EN

Analysis and editing articles: $\mathrm{MH}$

Data collection: FA, SS

The idea and design of the study and editing articles: $\mathrm{SGH}$

\section{Conflict of Interest}

"The authors declare that they have no competing interest".

\section{Funding}

The author (s) received no financial support for the research, authorship and/or publication of this article.

\section{References}

1- Di Bartolo PM, Rendón MJ. A critical examination of the construct of perfectionism and its relationship to mental health in Asian and African Americans using a cross-cultural framework. Clin Psychol Rev2012; 32(3): 139-52.

2- Eisenberg D, Downs MF, Golberstein E, Zivin K. Stigma and help seeking for mental health among college students. Med Care Res Rev2009; 66(5): 522-41. 3- Blanco C, Okuda M, Wright C, et al. Mental health of college students and their non-college-attending peers: results from the national epidemiologic study on alcohol and related conditions. Arch Gen Psychiatry2008; 65(12): 1429-37.

4- Nemati E, Habibi M, Rastak H. Mental health issues of student life: challenges, therapeutic approaches and constraints ahead on depression and suicide. $J$ Community Health. In Press.

5- Hunt J, Eisenberg D. Mental health problems and help-seeking behavior among college students. $J$ Adolesc Health2010; 46(1): 3-10.

6- Mesbahi Rezvan R, Zahedi O, Tabatabai M. Thanksgiving and mental health. First edition, Tehran: Publications saint; 2010.

7- Moalemi S, Bakhshani N, Raghiby M. Relationship between mental health, spiritual intelligence and dysfunctional thoughts the university of Sistan and Baluchestan. Journal of Mental Health2010; 12(48).

8- Ghobarybanab B, Zarea H, Esmaili M. The spiritual intelligence (SI) components from the perspective of Islam and west. International Research Journal of
Applied and Basic Sciences2007; 4(10): 3544-50

9- Kashdan TB, Nezlek JB. Whether, when, and how is spirituality related to well-being? Moving beyond single occasion questionnaires to understanding daily process. Pers Soc Psychol Bull2012; 38(11): 1523-35. 10- Pargament K I, Mahoney A. Spirituality: the search for the sacred. In Lopez SJ \& Snyder CR eds. Handbook of positive psychology (pp. 611-619). New York, NY: Oxford university press; 2009.

11- King DB. Personal meaning production as a component of spiritual intelligence. Proceeding of the 5th biennial international conference on personal meaning; 2008; July 24-27, Toronto, Ontario, Canada, 2008.

12- Sohrabi F. Basics of spiritual intelligence. Mental Health Journal 2008; 1(1): 14-18.

13- Yaghoubi A. The study of reation between spiritual intelligence and rate of happiness in Booali university students. Journal of Research in Educational Systems2010; 4( 9): 85-95.

14-King DB. Rethinking clams of spiritual intelligence: A definition, model, and measure. M.Sc. [dissertation]. Canada: Trent University, College of arts and sciences $2008 ; 32-48$

15- King DB, De Cicco TL. A viable model and self-report measure of spiritual, Trent University, Peterborough, Canada. International Journal of Transpersonal Studies2009;28:68-85.

16- Vaughan F. What is spiritual intelligence? Journal of Humanistic Psychology2002; 42(2):16-33.

17- Sisk DA, Torrance EP. Spiritual intelligence: developing higher conciousness: creative education foundation press. Piritual Intelligence: Developing higher consciousness. Buffalo,New York: Creative education foundation press; 2001.

18- Brown KW, Ryan RM. The benefits of being present: mindfulness and its role in psychological wellbeing. J Pers Soc Psychol2003: 84(4): 822-48.

19- Michalak J, Teismann T, Heidenreich T, et al. Buffering low self-esteem: the effect of mindful acceptance on the relationship between self-esteem and depression. Pers Individ Dif2011; 50: 751-4.

20- Bergomi C, Strohle G, Michalak J, Funke F, Berking M. Facing the dreaded: does mindfulness facilitate coping with distressing experiences? A moderator analysis. Cogn Behav Ther2013; 42(1): 2130.

21- Flugel Colle KF, Vincent A, Cha SS, et al. Measurement of quality of life and participant experience with the mindfulness based stress reduction program. Complement Ther Clin Pract2010; 16(1):3640.

22- Kieviet-Stijnen A, Visser A, Garssen B, et al. Mindfulness-based stress reduction training for 
oncology patients: patients' appraisal and changes in well being. Patient Educ Couns2008; 72(3): 436-42.

23- Tan LB, Martin G. Mind full or mindful: a report on mindfulness and psychological health in healthy adolescents. Int J Adolesc Youth2016; 21(1): 64-74.

24- Saadati H, Lashny L. Relationship spiritual intelligence and coping strategies. Journal of Rehabilitation2011;12(6): 75-81.

25- Roh MS, Jeon HJ, Kim H, et al. The prevalence and impact of depression among medical students: a nationwide cross-sectional study in south Korea. Acad Med2010; 85(8): 1384-90.

26- Michalec B, Keyes CL. A multidimensional perspective of the mental health of preclinical medical students. Psychol Health Med2013; 18(1): 89-97.

27- Schwenk TL, Davis L, Wimsatt LA. Depression, stigma, and suicidal ideation in medical students. JAMA2010; 304(11): 1181-90.

28- Aghayani Chavoshi A, Talebiyan D, Trkhvrany H, et al. The relationship between prayer and religious orientations and mental health. Journal of Behavioral Sciences2008; 2(2): 149-56.

29- Noorbala AA, Bagheri Yazdi SA, Muhammad $\mathrm{K}$. Validation of the general ealth questionnaire-28 aspsychiatric screening instruments in Tehran in2001. Journal Hakim Research2008; 11(4): 47-53.

30- Nemati E, Sadeghi MS, Ahmadi A. The relationship of perceived parenting with spiritual intelligence and mindfulness in students. Educational Research Islamic Azad University Bojnurd. In Press.

31- Kaviani H, Hatami N, Shafi Abadi A. The efficacy of mindfulness-based cognitive therapy for depression on quality of life (non-clinical). Journal New of Cognitive Science2008; 10(4): 39-48.

32- Brown KW, Ryan RM, Creswell JD. Addressing fundamental questions about mindfulness. Psychol Inq2007; 18(4): 272-81.

33- Morin CM. Cognitive-behavioral approaches to the treatment of insomnia. J Clin Psychiatry2004; 65(16): 33-40.

34- Nasr Esfahani N, Etemadi A. The relation between personality traits with spiritual intelligence and quality of life in students of AlameTabatabaie University (Iran). Journal of Research \& Health2012; 2 (2) :227-36.

35- Sharifi T, Sotoude Nia F. Relationship between national and religious identity of students with mental disorder. Proceedings of the sixth national conference on student mental health. Guilan: Guilan University 2012.

36- Hosseini SH, Sadeghi A, Rajab Zadeh R, et al. Mental health and associated factors in north Khorasan university of medical sciences in 2010. Journal Medical Sciences of North Khorasan University2011; 3(2):23-8. 37- Tavakoli MA, Chini Saz N, Alipour M. Mental health status of incoming students of Islamic Azad University of
Abadan 2006-2007 school year. Educational Research Islamic Azad University2009; 6(21): 43-72. 